Discussion Paper No. 715

\title{
GROWTH, STAGNATION AND STATUS PREFERENCE
}

\author{
Ryu-ichiro Murota \\ and \\ Yoshiyasu Ono
}

June 2008

The Institute of Social and Economic Research

Osaka University

6-1 Mihogaoka, Ibaraki, Osaka 567-0047, Japan 


\title{
Growth, Stagnation and Status Preference Ryu-ichiro Murota* and Yoshiyasu Ono ${ }^{\dagger}$
}

\begin{abstract}
We consider three objects of people's status preference, consumption, physical capital holding and money holding, and show that an economy grows or stagnates depending on which object people most seriously take as status. If the main object of status preference is consumption, a steady state with full employment is reached. If it is physical capital (viz. a producible asset), permanent growth with full employment occurs. However, if it is money (viz. an unproducible asset), stagnation with persistent unemployment arises.
\end{abstract}

JEL Classification: E12; E24; O41

Keywords: Status Preference; Persistent Unemployment; LongRun Growth

*School of Economics, Kinki University, 3-4-1 Kowakae, Higashi-Osaka, Osaka 5778502, JAPAN. E-mail: murota@eco.kindai.ac.jp.

$\dagger$ Institute of Social and Economic Research, Osaka University, 6-1 Mihogaoka, Ibaraki, Osaka 567-0047, JAPAN. E-mail: ono@iser.osaka-u.ac.jp. Ono's research is financially supported by the Grants-in-Aid for Scientific Research, JSPS. 


\section{Introduction}

Many economists (e.g., J. M. Keynes, A. Smith, and T. Veblen) have long pointed out that people care about their relative positions in society. For example, Keynes (1972, p. 326) states

Now it is true that the needs of human beings may seem to be insatiable. But they fall into two classes - those needs which are absolute in the sense that we feel them whatever the situation of our fellow human beings may be, and those which are relative in the sense that we feel them only if their satisfaction lifts us above, makes us feel superior to, our fellows. Needs of the second class, those which satisfy the desire for superiority, may indeed be insatiable; for the higher the general level, the higher still they are.

Recently, the literature on social status has been expanding and various factors that generate social status are analyzed. ${ }^{1}$ For instance, Corneo and Jeanne (1997a) and Rauscher (1997) model Veblen's (1922) conspicuous consumption, which signals high income and thus high status. Bakshi and Chen (1996), Clemens (2004), Cole, Mailath and Postlewaite (1992), Corneo and Jeanne (1997b), Fisher (2004, 2005), Futagami and Shibata (1998), Gong and Zou (2001), Long and Shimomura (2004), and Zou (1994, 1995, 1998) present models where social status comes from the relative or absolute level of physical capital or wealth holding. Fershtman, Murphy and Weiss (1996) and Kawamoto (2007) adopt the idea that the relative amount of human capital generates social status. Clark and Oswald (1998) more generally analyze the case where people's actions affect their positions in society.

\footnotetext{
${ }^{1}$ See, e.g., Weiss and Fershtman (1998) for a survey.
} 
We consider three objects of status preference together, viz. consumption (conspicuous consumption), physical capital (capitalist spirit) and money (miser Scrooge), and find that depending on which object people value most an economy exhibits quite different performances: converging to the full employment steady state without growth, persistent growth with full employment, stagnation with persistent unemployment, and unemployment growth.

Demand for producible objects creates employment. Thus, if people take consumption or physical capital holding to be more important than money holding as exhibiting social status, full employment is reached. In particular, if physical capital holding is the object, people continue to accumulate it and hence an economy perpetually grows, as in the capitalist-spirit economy discussed by Weber (1958). ${ }^{2}$ However, if money is the object, people do not sufficiently demand producibles, causing persistent unemployment to arise. It is in conformity with the following statement by Keynes (1936, p. 235):

Unemployment develops, that is to say, because people want the moon;- men cannot be employed when the object of desire (i.e. money) is something which cannot be produced and the demand for which cannot be readily choked off.

Is frugality beneficial to society? This is an important issue that has long been discussed. For example, Smith (1910, p. 304) states

Whatever, therefore, we may imagine the real wealth and revenue of a country to consist in, whether in the value of the annual produce of its land and labour, as plain reason seems to dictate; or in the quantity of the precious metals which circulate within it,

\footnotetext{
${ }^{2}$ Zou (1994) proposes a model of such capitalist spirit and shows that perpetual capital growth occurs.
} 
as vulgar prejudices suppose; in either view of the matter, every prodigal appears to be a public enemy, and every frugal man a public benefactor.

Keynes (1936, chapter 23) criticizes it by quoting from B. Laffemas, W. Petty, N. Barbon, J. Cary, B. Mandeville, J. A. Hobson, A. F. Mummery and T. R. Malthus, and insists that frugality causes unemployment to occur. In the present paper we show that in the presence of status preference frugality can be virtue or vice, depending on which asset people want to hold as exhibiting status.

The remainder of the present paper is organized as follows. Section 2 presents a model that considers three objects of people's status preference together. Section 3 shows how people's status preference influences the dynamic behavior of the economy. Section 4 concludes. Proofs of dynamic stabilities under various growth and stagnation patterns are set out in appendices.

\section{The Model}

\section{$2.1 \quad$ Households}

We consider an economy populated by identical households whose size is normalized to unity. The representative household's utility depends on not only consumption $c_{t}$ and real money holding $m_{t}$ but also social status $s_{t}$ :

$$
U=\int_{0}^{\infty}\left[u\left(c_{t}\right)+v\left(m_{t}\right)+\chi\left(s_{t}\right)\right] \exp (-\rho t) \mathrm{d} t
$$

where $\rho(>0)$ is the subjective discount rate and the felicity function satisfies 


$$
\begin{aligned}
& u^{\prime}(\cdot)>0, \quad u^{\prime \prime}(\cdot)<0, \quad u^{\prime}(0)=\infty, \quad u^{\prime}(\infty)=0 \\
& v^{\prime}(\cdot)>0, \quad v^{\prime \prime}(\cdot)<0, \quad v^{\prime}(0)=\infty, \quad v^{\prime}(\infty)=0 \\
& \lim _{m_{t} \rightarrow 0} v^{\prime}\left(m_{t}\right) m_{t}>0, \quad \lim _{m_{t} \rightarrow \infty} v^{\prime \prime}\left(m_{t}\right) m_{t}=0 \\
& \chi^{\prime}(\cdot)>0, \quad \chi^{\prime \prime}(\cdot)<0 .
\end{aligned}
$$

Social status $s_{t}$ consists of three factors, viz. consumption, physical capital holding and real money holding, each in excess of the social average:

$$
s_{t}=\theta_{c}\left(c_{t}-\bar{c}_{t}\right)+\theta_{k}\left(k_{t}-\bar{k}_{t}\right)+\theta_{m}\left(m_{t}-\bar{m}_{t}\right)
$$

where $\bar{c}_{t}, \bar{k}_{t}$ and $\bar{m}_{t}$ represent respective social averages. $\theta_{c}, \theta_{k}$ and $\theta_{m}$ indicate the magnitude of each factor's contribution to social status, representing conspicuous consumption, capitalist spirit and miser Scrooge respectively.

Real total asset $a_{t}$ consists of physical capital and money:

$$
a_{t}=k_{t}+m_{t}
$$

The flow budget equation is

$$
\dot{a}_{t}=r_{t} k_{t}-\pi_{t} m_{t}+w_{t} l_{t}+\xi_{t}-c_{t}
$$

where $r_{t}$ is the capital rent, $w_{t}$ is the real wage, $\pi_{t}\left(\equiv \dot{P}_{t} / P_{t}\right)$ is the inflation rate of commodity price $P_{t}$, and $l_{t}$ is the realized amount of labor supply. Each household's labor endowment is assumed to be unity. However, since there may be unemployment, under the short-side assumption $l_{t}$ is given by

$$
l_{t}=\min \left\{l_{t}^{d}, 1\right\}
$$

where $l_{t}^{d}$ represents labor demand. $\xi_{t}$ is the real profit income that the individual receives from firms. As is shown later, in the presence of excess labor 
demand real profit $\xi_{t}$ is positive even under perfect competition and a linear homogeneous production function.

The individual maximizes $U$ subject to (3) and (4). The first-order optimal conditions are

$$
\begin{gathered}
u^{\prime}\left(c_{t}\right)+\theta_{c} \chi^{\prime}\left(s_{t}\right)=\lambda_{t}, \\
v^{\prime}\left(m_{t}\right)+\theta_{m} \chi^{\prime}\left(s_{t}\right)-\pi_{t} \lambda_{t}=\eta_{t}, \\
\theta_{k} \chi^{\prime}\left(s_{t}\right)+r_{t} \lambda_{t}=\eta_{t}, \\
\dot{\lambda}_{t}-\rho \lambda_{t}=-\eta_{t},
\end{gathered}
$$

and the transversality condition is

$$
\lim _{t \rightarrow \infty} \lambda_{t} a_{t} \exp (-\rho t)=0
$$

where $\lambda_{t}$ and $\eta_{t}$ are the co-state variable associated with (4) and the Lagrangian multiplier associated with (3) respectively, and $s_{t}$ is given by (2).

\section{$2.2 \quad$ Firms}

The firm sector has the following linear homogeneous production function:

$$
y_{t}=F\left(k_{t}, l_{t}\right)=f\left(k_{t} / l_{t}\right) l_{t},
$$

where $f(\cdot)$ satisfies

$$
f(0)=0, \quad f(\infty)=\infty, \quad f^{\prime}(\cdot)>0, \quad f^{\prime \prime}(\cdot)<0, \quad f^{\prime}(0)=\infty, \quad f^{\prime}(\infty)=0 .
$$

Under perfect competition it determines $l_{t}^{d}$ so as to satisfy

$$
w_{t}=f\left(k_{t} / l_{t}^{d}\right)-f^{\prime}\left(k_{t} / l_{t}^{d}\right)\left(k_{t} / l_{t}^{d}\right)
$$

Thus, $k_{t} / l_{t}^{d}$ is expressed as a function of only $w_{t}$ :

$$
k_{t} / l_{t}^{d}=h\left(w_{t}\right), \quad h(\infty)=\infty, \quad h^{\prime}\left(w_{t}\right)=-\frac{1}{f^{\prime \prime}\left(h\left(w_{t}\right)\right) h\left(w_{t}\right)} \geq 0 .
$$


Substituting (12) into (5) gives

$$
l_{t}=\min \left\{k_{t} / h\left(w_{t}\right), 1\right\} .
$$

From (5) and (11), we find

$$
\begin{aligned}
& w_{t}=f\left(k_{t} / l_{t}\right)-f^{\prime}\left(k_{t} / l_{t}\right)\left(k_{t} / l_{t}\right) \text { if } 1 \geq l_{t}^{d}\left(=l_{t}\right), \\
& w_{t}<f\left(k_{t}\right)-f^{\prime}\left(k_{t}\right) k_{t} \text { if } l_{t}^{d}>1\left(=l_{t}\right) .
\end{aligned}
$$

Whereas the labor market adjustment is sluggish, the capital market adjustment is assumed to be perfect and thus the capital rent always equals the marginal productivity of capital for any $l_{t}$ :

$$
r_{t}=f^{\prime}\left(k_{t} / l_{t}\right)
$$

Since real profit $\xi_{t}$ is

$$
\xi_{t}=f\left(k_{t} / l_{t}\right) l_{t}-r_{t} k_{t}-w_{t} l_{t},
$$

using (14) and (15) we obtain

$$
\begin{aligned}
& \xi_{t}=0 \text { if } 1 \geq l_{t}^{d}\left(=l_{t}\right), \\
& \xi_{t}>0 \text { if } l_{t}^{d}>1\left(=l_{t}\right) .
\end{aligned}
$$

When $\xi_{t}$ is strictly positive, it is transferred to households, as shown by (4).

\subsection{Dynamics}

Since households are identical, $c_{t}, k_{t}$ and $m_{t}$ equal each social average:

$$
c_{t}=\bar{c}_{t}, k_{t}=\bar{k}_{t}, m_{t}=\bar{m}_{t}
$$

Therefore, social status $s_{t}$ given by (2) is always

$$
s_{t}=0
$$


i.e., a desire for social status is never satiated.

From (6)-(8), (15) and (16), we obtain

$$
f^{\prime}\left(k_{t} / l_{t}\right)+\frac{\theta_{k} \chi^{\prime}(0)}{u^{\prime}\left(c_{t}\right)+\theta_{c} \chi^{\prime}(0)}=-\pi_{t}+\frac{v^{\prime}\left(m_{t}\right)}{u^{\prime}\left(c_{t}\right)+\theta_{c} \chi^{\prime}(0)}+\frac{\theta_{m} \chi^{\prime}(0)}{u^{\prime}\left(c_{t}\right)+\theta_{c} \chi^{\prime}(0)},
$$

where the left-hand side represents the total benefit of holding physical capital, consisting of the capital rent and the utility of social status, and the right-hand side represents the net benefit of holding money, consisting of the utility of liquidity and that of social status minus the inflation cost. From (6), (8), (9), (15) and (16), the dynamics of consumption is given by

$$
\frac{\dot{c}_{t}}{c_{t}}=\sigma\left(c_{t}\right)\left[f^{\prime}\left(k_{t} / l_{t}\right)+\frac{\theta_{k} \chi^{\prime}(0)}{u^{\prime}\left(c_{t}\right)+\theta_{c} \chi^{\prime}(0)}-\rho\right]
$$

where $\sigma\left(c_{t}\right) \equiv-\left[u^{\prime}\left(c_{t}\right)+\theta_{c} \chi^{\prime}(0)\right] /\left[u^{\prime \prime}\left(c_{t}\right) c_{t}\right]>0$.

Nominal money supply $M_{t}$ is assumed to be constant at $M$ and hence $\dot{m}_{t} / m_{t}=-\pi_{t}$. Substituting $\pi_{t}$ given by (17) into this equation yields

$$
\frac{\dot{m}_{t}}{m_{t}}=-\frac{v^{\prime}\left(m_{t}\right)}{u^{\prime}\left(c_{t}\right)+\theta_{c} \chi^{\prime}(0)}+\frac{\chi^{\prime}(0)\left(\theta_{k}-\theta_{m}\right)}{u^{\prime}\left(c_{t}\right)+\theta_{c} \chi^{\prime}(0)}+f^{\prime}\left(k_{t} / l_{t}\right) \text {. }
$$

Nominal wage adjustment is assumed to be sluggish in the following manner:

$$
\frac{\dot{W}_{t}}{W_{t}}=\gamma\left(l_{t}^{d}-1\right)
$$

where the initial level of nominal wage $W_{0}$ is historically given. ${ }^{3}$ Since $\dot{w}_{t} / w_{t}=\dot{W}_{t} / W_{t}-\pi_{t},(12),(17)$ and (20) lead to

$$
\frac{\dot{w}_{t}}{w_{t}}=\gamma\left(\frac{k_{t}}{h\left(w_{t}\right)}-1\right)-\frac{v^{\prime}\left(m_{t}\right)}{u^{\prime}\left(c_{t}\right)+\theta_{c} \chi^{\prime}(0)}+\frac{\chi^{\prime}(0)\left(\theta_{k}-\theta_{m}\right)}{u^{\prime}\left(c_{t}\right)+\theta_{c} \chi^{\prime}(0)}+f^{\prime}\left(k_{t} / l_{t}\right) .
$$

\footnotetext{
${ }^{3}$ Many economists have explored how the real or the nominal wage is adjusted. Although this issue is interesting and important, the present paper does not address the issue and assumes the simple adjustment of the nominal wage, in order to focus on influences of status preference on the dynamic behavior of the economy.
} 
Commodity price $P_{t}$ perfectly adjusts so that the commodity market is always in equilibrium:

$$
\dot{k}_{t}=f\left(k_{t} / l_{t}\right) l_{t}-c_{t}
$$

(18), (19), (21) and (22), where $l_{t}$ is given by (13), formulate an autonomous dynamic system with respect to $c_{t}, m_{t}, w_{t}$ and $k_{t}$.

\section{Economic Consequences of Status Prefer- ence}

This section demonstrates the relationship between people's status prefer-

ence represented by $\theta_{c}, \theta_{k}$ and $\theta_{m}$ and the dynamic behavior of an economy, viz. convergence to the full employment steady state, persistent growth with full employment, persistent growth with unemployment, and stagnation with persistent unemployment.

\subsection{Full Employment Steady State}

Let us first examine the condition for the full employment steady state to be reached. From (18), (19), (21) and (22) in which

$$
l=l^{d}=1, \quad \dot{c}=0, \quad \dot{k}=0, \quad \dot{m}=0, \quad \dot{w}=0,
$$

the full employment steady state is given by

$$
\begin{gathered}
c^{*}=f\left(k^{*}\right), \\
\rho=f^{\prime}\left(k^{*}\right)+\frac{\theta_{k} \chi^{\prime}(0)}{u^{\prime}\left(f\left(k^{*}\right)\right)+\theta_{c} \chi^{\prime}(0)}\left(\equiv \varphi\left(k^{*}\right)\right), \\
\rho=\frac{v^{\prime}\left(m^{*}\right)}{u^{\prime}\left(f\left(k^{*}\right)\right)+\theta_{c} \chi^{\prime}(0)}+\frac{\theta_{m} \chi^{\prime}(0)}{u^{\prime}\left(f\left(k^{*}\right)\right)+\theta_{c} \chi^{\prime}(0)}\left(\equiv \phi\left(m^{*}, k^{*}\right)\right),
\end{gathered}
$$

where ${ }^{*}$ represents each value in the full employment steady state. The second and third equations imply equality among the time preference rate, 
the marginal benefit of holding physical capital $k$ and that of holding money $m$. The marginal benefit of $k$ is the sum of the marginal productivity and the marginal contribution to status while that of $m$ is the sum of the marginal utility of liquidity and the marginal contribution to status.

Since the marginal benefit of $k$ is naturally assumed to decrease as $k$ increases, $\varphi(\cdot)$ and $\phi(\cdot, \cdot)$ given in $(23)$ satisfy

$$
\begin{gathered}
\varphi(0)=\infty, \quad \varphi(\infty)=\frac{\theta_{k}}{\theta_{c}}, \quad \varphi^{\prime}=f^{\prime \prime}-\frac{\theta_{k} \chi^{\prime}(0) u^{\prime \prime} f^{\prime}}{\left[u^{\prime}+\theta_{c} \chi^{\prime}(0)\right]^{2}}<0 ; \\
\phi\left(0, k^{*}\right)=\infty, \quad \phi\left(\infty, k^{*}\right)=\frac{\theta_{m} \chi^{\prime}(0)}{u^{\prime}\left(f\left(k^{*}\right)\right)+\theta_{c} \chi^{\prime}(0)}, \\
\frac{\partial \phi}{\partial m}<0, \quad \frac{\partial \phi}{\partial k}>0,
\end{gathered}
$$

and hence $k^{*}$ and $m^{*}$ uniquely exist if $\theta_{c}$ is so large as to satisfy

$$
\frac{\theta_{k}}{\theta_{c}} \leq \rho, \quad \frac{\theta_{m} \chi^{\prime}(0)}{u^{\prime}\left(f\left(k^{*}\right)\right)+\theta_{c} \chi^{\prime}(0)} \leq \rho
$$

Furthermore, in appendix A it is proven that the dynamic path along which the full employment steady state is reached is uniquely determined. Thus,

Proposition 1. The full employment steady state represented by (23) is reached if the contribution of consumption to social status, $\theta_{c}$, is so large that (25) is valid.

The area of $\theta_{k}$ and $\theta_{m}$ satisfying (25) is given by region $\mathrm{A}$ in figure 1 . Note that the border of the second inequality of (25) forms a negative relationship between $\theta_{k}$ and $\theta_{m}$. It is because from the second equation of (23) and the property that $\varphi^{\prime}<0$ given in (24) a rise in $\theta_{k}$ increases $k^{*}$ and hence reduces $u^{\prime}\left(f\left(k^{*}\right)\right)$, which decreases $\theta_{m}$ that equalizes both sides of the second property of $(25)$. 


\subsection{Permanent Growth}

Let us next treat the case where the full employment steady state does not exist. In this subsection it will be shown that if

$$
\frac{\theta_{k}}{\theta_{c}}>\rho, \quad \theta_{k} \geq \theta_{m}
$$

steady growth occurs although the marginal productivity of capital decreasingly converges to zero as $k$ expands. The first property of (26) implies that the marginal benefit of holding capital dominates the time preference rate even when capital holding expands to infinity whereas the second property implies that people take capital more seriously than money as a measure of social status.

Under (26) capital $k$ continues to accumulate and eventually $f^{\prime}(\cdot)$ declines to zero while $c$ and $m$ approach respective constant levels that make $\dot{c}$ given by (18) and $\dot{m}$ given by (19) zero:

$$
\begin{gathered}
\frac{\theta_{k} \chi^{\prime}(0)}{u^{\prime}(c)+\theta_{c} \chi^{\prime}(0)}=\rho, \\
\frac{\theta_{k} \chi^{\prime}(0)}{u^{\prime}(c)+\theta_{c} \chi^{\prime}(0)}=\frac{v^{\prime}(m)}{u^{\prime}(c)+\theta_{c} \chi^{\prime}(0)}+\frac{\theta_{m} \chi^{\prime}(0)}{u^{\prime}(c)+\theta_{c} \chi^{\prime}(0)} .
\end{gathered}
$$

Since $\dot{w} / w=0$, as shown in appendix B, from (21) and (28) the labor market reaches full employment:

$$
\left(l^{d}=\right) \frac{k}{h(w)}=1
$$

In appendix $\mathrm{C}$ it is proven that there is a unique equilibrium path that reaches the steady state given above.

Note that $k$ continues to accumulate and yet transversality condition (10) is valid, as proven below. Since $m$ is finite and $a=k+m$,

$$
\lim _{t \rightarrow \infty} \frac{\dot{\lambda}_{t}}{\lambda_{t}}+\frac{\dot{a}_{t}}{a_{t}}-\rho \leq \lim _{t \rightarrow \infty} \frac{\dot{\lambda}_{t}}{\lambda_{t}}+\frac{\dot{k}_{t}}{k_{t}}-\rho .
$$


Since $c$ is finite and $k$ continues to expand, from (22) we obtain

$$
\lim _{t \rightarrow \infty} \frac{\dot{k}_{t}}{k_{t}}=\lim _{k \rightarrow \infty}\left[\frac{f(k / l)}{k / l}-\frac{c}{k}\right]=\lim _{k / l \rightarrow \infty} f^{\prime}(k / l)-\lim _{k \rightarrow \infty} \frac{c}{k}=0,
$$

where $l=\min \left\{l^{d}, 1\right\}$ and the second equality results from de l'Hôpital's rule. Thus, using (6), (8), (9), (15) and (30) one finds

$$
\lim _{t \rightarrow \infty} \frac{\dot{\lambda}_{t}}{\lambda_{t}}+\frac{\dot{a}_{t}}{a_{t}}-\rho \leq-\frac{\theta_{k} \chi^{\prime}(0)}{u^{\prime}(c)+\theta_{c} \chi^{\prime}(0)}<0,
$$

which implies the validity of (10).

Such full employment growth occurs only if initial price level $P_{0}$ (and hence initial real money balances $m_{0}$ ) jumps to the value leading to it since the dynamic path is saddle point stable as shown by appendix C. If $P_{0}$ jumps to a lower level than the value, $P$ continues to fall and $m$ expands to infinity. ${ }^{4}$ We next show that a continuum of such paths is equilibrium paths under a certain condition. In this case not only full employment growth but also unemployment growth is possible.

The above case in fact occurs if $\theta_{k}$ and $\theta_{m}$ satisfy (26) and

$$
\frac{\theta_{m}}{\theta_{k}} \geq \frac{\rho-\gamma}{\rho}
$$

which are shown by region B in figure 1 . Since both $v^{\prime}(m)$ and $f^{\prime}(k / l)$ converge to zero along the deflationary paths, from (19) and (21) in the state in which $\dot{w} / w=0,{ }^{5}$ we find

$$
\begin{aligned}
& \frac{\dot{m}}{m}=-\pi=-\gamma(l-1) \geq 0 \\
& \frac{\left(\theta_{k}-\theta_{m}\right) \chi^{\prime}(0)}{u^{\prime}(c)+\theta_{c} \chi^{\prime}(0)}=-\gamma(l-1) .
\end{aligned}
$$

\footnotetext{
${ }^{4}$ If $P_{0}$ jumps to a higher level than the value, $m$ continues to decline. From (19), such inflationary paths are ruled out since from (1) $\lim _{m_{t} \rightarrow 0} v^{\prime}\left(m_{t}\right) m_{t}>0$. See, e.g., Blanchard and Fischer (1989, chapter 5) for the infeasibility of such hyper-inflationary paths.

${ }^{5}$ See appendix $\mathrm{B}$ for the property that $\dot{w} / w=0$.
} 
Since $m$ continues to expand, as shown by the first property of (32), (28) is replaced by the second equation of (32) while (27) is still valid. Substituting (27) into the second property of (32) yields

$$
\begin{aligned}
l & =1-\left(1-\frac{\theta_{m}}{\theta_{k}}\right) \frac{\rho}{\gamma}(\leq 1 \text { under }(26)) \\
& =\left(\frac{\theta_{m}}{\theta_{k}}-\frac{\rho-\gamma}{\rho}\right) \frac{\rho}{\gamma}(\geq 0 \text { under }(31)),
\end{aligned}
$$

implying that unemployment persists. Although both $k$ and $m$ expand to infinity, the transversality condition is valid since from $(6),(7),(9),(19)$ and (30) we obtain

$$
\lim _{t \rightarrow \infty} \frac{\dot{\lambda}_{t}}{\lambda_{t}}+\frac{\dot{a}_{t}}{a_{t}}-\rho \leq \lim _{t \rightarrow \infty} \frac{\dot{\lambda}_{t}}{\lambda_{t}}+\frac{\dot{m}_{t}}{m_{t}}-\rho=-\frac{\theta_{m} \chi^{\prime}(0)}{u^{\prime}(c)+\theta_{c} \chi^{\prime}(0)}<0 .
$$

Along these paths people continue to accumulate capital and money so that they raise their social status. Since money is unproducible, a desire for it does not create any labor demand and causes persistent unemployment and deflation to occur. Furthermore, the stability type of unemployment growth is sink, as shown in appendix D, and hence there is a continuum of equilibrium paths with permanent growth and unemployment.

We summarize the preceding discussion below.

Proposition 2. Under (26) and (31) there are two types of dynamic paths: a unique path that leads to permanent growth with full employment and a continuum of paths that lead to permanent growth with unemployment.

This proposition suggests that unemployment growth will most probably occur.

If (26) is valid and (31) is violated, the value of $l$ given by (33) is less than zero and hence the deflationary paths are infeasible. This is the case where the relative preference for money over physical capital $\left(\theta_{m} / \theta_{k}\right)$ is small 
enough. People desire to accumulate physical capital rather than money and hence full employment is realized. This case is represented by region $\mathrm{C}$ in figure 1. Note that it appears only if $\rho>\gamma$, that is, preference for consumption $(\rho)$ dominates the benefit of holding money due to deflation $(\gamma)$

Proposition 3. Permanent growth with full employment occurs if the contribution of capital holding to social status, $\theta_{k}$, is so high as to satisfy (26) and violate (31).

\subsection{Stagnation with Unemployment}

Let us finally consider the case illustrated by region $\mathrm{D}$ in figure 1 . In this case

$$
\begin{gathered}
\frac{\theta_{m} \chi^{\prime}(0)}{u^{\prime}\left(f\left(k^{*}\right)\right)+\theta_{c} \chi^{\prime}(0)}>\rho \quad\left(\text { if } \theta_{k} \leq \rho \theta_{c}\right), \\
\theta_{m}>\theta_{k},
\end{gathered}
$$

where $k^{*}$ is given by the second equation of $(23)$. Note that $k^{*}$ exists if $\theta_{k} \leq \rho \theta_{c}$, as shown by (24) and (25). The first property of (34) implies that the marginal benefit of money is always higher than the time preference rate and hence money is preferred to consumption whereas the second one implies that money is more important than capital as a source of social status. Thus, $c$ and $k$ stay finite while $m$ continues to expand and $l=l^{d}<1$. From (18), (19), (21) and (22), the steady state in this case is given by

$$
\begin{gathered}
c=f(k / l) l, \\
f^{\prime}(k / l)+\frac{\theta_{k} \chi^{\prime}(0)}{u^{\prime}(c)+\theta_{c} \chi^{\prime}(0)}=-\gamma(l-1)+\frac{\theta_{m} \chi^{\prime}(0)}{u^{\prime}(c)+\theta_{c} \chi^{\prime}(0)}, \\
\rho=-\gamma(l-1)+\frac{\theta_{m} \chi^{\prime}(0)}{u^{\prime}(c)+\theta_{c} \chi^{\prime}(0)}, \\
\frac{\dot{m}}{m}=-\pi=-\gamma(l-1)>0 .
\end{gathered}
$$


Substituting the first equation of (35) into the second equation yields $k / l$ as a function of $l$, denoted by $g(l)$ :

$$
\begin{aligned}
f^{\prime}(k / l)+\frac{\theta_{k} \chi^{\prime}(0)}{u^{\prime}(f(k / l) l)+\theta_{c} \chi^{\prime}(0)} & =-\gamma(l-1)+\frac{\theta_{m} \chi^{\prime}(0)}{u^{\prime}(f(k / l) l)+\theta_{c} \chi^{\prime}(0)} \\
& \Rightarrow k / l=g(l) .
\end{aligned}
$$

From $g(l)$ given above and the first and third equations of $(35), l$ is determined so that it satisfies

$$
G(l) \equiv-\gamma(l-1)+\frac{\theta_{m} \chi^{\prime}(0)}{u^{\prime}(f(g(l)) l)+\theta_{c} \chi^{\prime}(0)}=\rho,
$$

where from the definitions of $\varphi(\cdot)$ and $\phi(\cdot, \cdot)$ given in $(23) G(\cdot)$ satisfies

$$
\begin{aligned}
& G(0)=\gamma \\
& G(1)=\phi(\infty, g(1))=\varphi(g(1)) .
\end{aligned}
$$

Once $l$ is determined, therefore, $c$ and $k$ are determined and the steady-state deflation rate takes the value given by the last equation of (35).

Let us find the condition under which such $l$ exists within $(0,1)$. From (24) and the second property of (34),

$$
\begin{gathered}
\varphi(0)>\phi(\infty, 0) \\
\varphi(\infty)\left(=\theta_{k} / \theta_{c}\right)<\phi(\infty, \infty)\left(=\theta_{m} / \theta_{c}\right), \\
\varphi^{\prime}(k)<0, \quad \frac{\partial \phi(\infty, k)}{\partial k}>0 .
\end{gathered}
$$

Therefore, there is a unique $g(1)$ that satisfies the second property of (37). If $\rho<\theta_{k} / \theta_{c}$, where the right-hand side is the lower bound of $\varphi(\cdot)$, as is clear from (38), it is obvious that $\rho<\varphi(g(1))$ and thus from (36) and (37) $G(l)<G(1)$. If $\theta_{k} / \theta_{c} \leq \rho$, from the second and third equations of (23) and the first property of (34),

$$
\rho=\varphi\left(k^{*}\right)<\phi\left(\infty, k^{*}\right)
$$


Since this property, the second property of (37) and the first property of (38) yield

$$
0<g(1)<k^{*}
$$

and $\varphi^{\prime}(k)<0$, as shown in (38), we find

$$
\left(\varphi\left(k^{*}\right)=\right) \rho<\varphi(g(1)) .
$$

Thus, from (36) and (37) $G(l)<G(1)$.

Having established that always $G(l)<G(1)$ and assuming the steady state to be unique, we find that in order for $l$ given by (36) to exist within $(0,1) G(0)$ must be lower than $G(l)$. From (36) and the first property of (37) this condition is equivalent to

$$
\rho>\gamma
$$

Since $G(0)<G(l)<G(1)$ and (36) gives a unique solution for $l$, we find

$$
G^{\prime}(l)>0
$$

Since $\dot{k}=0$ and $v^{\prime}(m)=0$ in the present steady state, from (6), (7), (9) and (19) we obtain

$$
\lim _{t \rightarrow \infty} \frac{\dot{\lambda}_{t}}{\lambda_{t}}+\frac{\dot{a}_{t}}{a_{t}}-\rho \leq \lim _{t \rightarrow \infty} \frac{\dot{\lambda}_{t}}{\lambda_{t}}+\frac{\dot{m}_{t}}{m_{t}}-\rho=-\frac{\theta_{m} \chi^{\prime}(0)}{u^{\prime}(c)+\theta_{c} \chi^{\prime}(0)}<0,
$$

which represents the validity of the transversality condition. In appendix E it is shown that there is a unique equilibrium path and hence

Proposition 4. A steady state with persistent unemployment without growth is reached if (39) is valid and the contribution of money holding to social status, $\theta_{m}$, is so large as to satisfy (34). 
If money is the main object of status preference, households permanently accumulate it whereas consumption and capital converge to respective finite levels. Since money demand creates no employment, unemployment persists. $^{6}$

Let us finally note that, if (39) does not hold, the case mentioned in proposition 2 is always valid under (26), the case mentioned in proposition 3 disappears, and $l$ given by (36) does not exist. Thus, region $\mathrm{C}$ in figure 1 disappears and in region $\mathrm{D}$ there is no equilibrium path. This case is illustrated by figure 2 .

\section{Concluding Remarks}

We consider an economy in which there are three objects of people's status preference, consumption, capital and money, and nominal wages adjust in a sluggish manner. If the main object of status preference is producible, viz. consumption or physical capital, labor demand is created and hence full employment is reached. In particular, if physical capital is most desired, endogenous and permanent capital growth occurs even under decreasing returns to capital. This is in conformity with Max Weber's capitalist-spirit economy. However, if people take money as the most important object of status, no demand for labor is created and hence persistent unemployment and deflation occur. This is consistent with what Keynes (1936, p. 235) states.

Adam Smith considers frugality to be beneficial since it urges people to accumulate physical capital and generate permanent growth. In contrast, John M. Keynes regards it as harmful since it keeps people from consumption

\footnotetext{
${ }^{6}$ This result is similar to Ono $(1994,2001)$, who shows that unemployment arises as a steady-state phenomenon if utility of money holding is insatiable.
} 
and leads to unemployment. We find that it can be virtue or vice, depending on which object people most seriously take as a measure of social status. If the object is physical capital, permanent growth arises. If it is money, persistent stagnation occurs and people are left unemployed. 


\section{Appendix A Stability of the Full Employment Steady State}

We first examine the case where excess labor demand arises along the path that converges to the steady state represented by (23). Linearizing (18), (19), (21) and (22), where $l_{t}=1<l_{t}^{d}$, in the neighborhood where $c_{t}=c^{*}, k_{t}=k^{*}$, $w_{t}=w^{*}\left(=f\left(k^{*}\right)-f^{\prime}\left(k^{*}\right) k^{*}\right)$ and $m_{t}=m^{*}$ and applying (12) and (23) to the results yields the characteristic equation of the dynamics of $\left(c_{t}, k_{t}, w_{t}, m_{t}\right)$ :

$$
\begin{array}{cccc}
-\frac{\theta_{k} \chi^{\prime}(0) \sigma c^{*} u^{\prime \prime}}{\left[u^{\prime}+\theta_{c} \chi^{\prime}(0)\right]^{2}}-z & \sigma c^{*} f^{\prime \prime} & 0 & 0 \\
-1 & f^{\prime}-z & 0 & 0 \\
-\frac{\left[\chi^{\prime}(0)\left(\theta_{k}-\theta_{m}\right)-v^{\prime}\right] w^{*} u^{\prime \prime}}{\left[u^{\prime}+\theta_{c} \chi^{\prime}(0)\right]^{2}} & w^{*} f^{\prime \prime}+\frac{\gamma w^{*}}{k^{*}} & \frac{\gamma w^{*}}{f^{\prime \prime} k^{* 2}}-z & -\frac{w^{*} v^{\prime \prime}}{u^{\prime}+\theta_{c} \chi^{\prime}(0)} \\
-\frac{\left[\chi^{\prime}(0)\left(\theta_{k}-\theta_{m}\right)-v^{\prime}\right] m^{*} u^{\prime \prime}}{\left[u^{\prime}+\theta_{c} \chi^{\prime}(0)\right]^{2}} & m^{*} f^{\prime \prime} & 0 & -\frac{m^{*} v^{\prime \prime}}{u^{\prime}+\theta_{c} \chi^{\prime}(0)}-z
\end{array} \mid=0,
$$

where $z$ denotes a characteristic root. It reduces to

$$
\left(z^{2}-\kappa z+\sigma c^{*} \varphi^{\prime}\right)\left(\frac{\gamma w^{*}}{f^{\prime \prime} k^{*^{2}}}-z\right)\left(-\frac{m^{*} v^{\prime \prime}}{u^{\prime}+\theta_{c} \chi^{\prime}(0)}-z\right)=0,
$$

where

$$
\kappa \equiv f^{\prime}-\frac{\theta_{k} \chi^{\prime}(0) \sigma c^{*} u^{\prime \prime}}{\left[u^{\prime}+\theta_{c} \chi^{\prime}(0)\right]^{2}} .
$$

Thus, besides the following two roots:

$$
z=\frac{\gamma w^{*}}{f^{\prime \prime} k^{*^{2}}}<0, \quad z=-\frac{m^{*} v^{\prime \prime}}{u^{\prime}+\theta_{c} \chi^{\prime}(0)}>0,
$$

there are two roots, $z_{1}$ and $z_{2}$, which using (24) one finds to satisfy

$$
z_{1} z_{2}=\sigma c^{*} \varphi^{\prime}<0
$$

implying that the characteristic equation has two positive and two negative roots. Note that $c_{0}$ is jumpable, $k_{0}$ is unjumpable, and the degree of freedom 
of choosing the initial level of $m_{t}$ and $w_{t}$ is one since once $P_{0}$ is chosen then both of $m_{0}\left(=M / P_{0}\right)$ and $w_{0}\left(=W_{0} / P_{0}\right)$ are determined. Therefore, the dynamic path is uniquely determined.

Next, we treat the case where excess labor supply arises $\left(l_{t}=k_{t} / h\left(w_{t}\right)<\right.$ 1) in the interim state. By linearizing (18), (19), (21) and (22) in the neighborhood where $c_{t}=c^{*}, k_{t}=k^{*}, w_{t}=w^{*}$ and $m_{t}=m^{*}$, and applying (12) and (23) to the results, we obtain the following characteristic equation of the dynamics of $\left(c_{t}, k_{t}, w_{t}, m_{t}\right)$ :

$\left|\begin{array}{cccc}-\frac{\theta_{k} \chi^{\prime}(0) \sigma c^{*} u^{\prime \prime}}{\left[u^{\prime}+\theta_{c} \chi^{\prime}(0)\right]^{2}}-z & 0 & -\frac{\sigma c^{*}}{k^{*}} & 0 \\ -1 & \frac{f}{k^{*}}-z & \frac{f-f^{\prime} k^{*}}{f^{\prime \prime} k^{* 2}} & 0 \\ -\frac{\left[\chi^{\prime}(0)\left(\theta_{k}-\theta_{m}\right)-v^{\prime}\right] w^{*} u^{\prime \prime}}{\left[u^{\prime}+\theta_{c} \chi^{\prime}(0)\right]^{2}} & \frac{\gamma w^{*}}{k^{*}} & -\frac{w^{*}}{k^{*}}+\frac{\gamma w^{*}}{f^{\prime \prime} k^{* 2}}-z & -\frac{w^{*} v^{\prime \prime}}{u^{\prime}+\theta_{c} \chi^{\prime}(0)} \\ -\frac{\left[\chi^{\prime}(0)\left(\theta_{k}-\theta_{m}\right)-v^{\prime}\right] m^{*} u^{\prime \prime}}{\left[u^{\prime}+\theta_{c} \chi^{\prime}(0)\right]^{2}} & 0 & -\frac{m^{*}}{k^{*}} & -\frac{m^{*} v^{\prime \prime}}{u^{\prime}+\theta_{c} \chi^{\prime}(0)}-z\end{array}\right|=0$.

It reduces to

$$
z^{4}+B_{3} z^{3}+B_{2} z^{2}+B_{1} z+B_{0}=0
$$

where using (24) we find $B_{0}$ to satisfy

$$
B_{0}=-\frac{\gamma \sigma c^{*} w^{*} m^{*} v^{\prime \prime} \varphi^{\prime}}{f^{\prime \prime} k^{*^{2}}\left[u^{\prime}+\theta_{c} \chi^{\prime}(0)\right]}>0,
$$

and using (14) we find $B_{3}$ to be

$$
B_{3}=\frac{\theta_{k} \chi^{\prime}(0) \sigma c^{*} u^{\prime \prime}}{\left[u^{\prime}+\theta_{c} \chi^{\prime}(0)\right]^{2}}-f^{\prime}-\frac{\gamma w^{*}}{f^{\prime \prime} k^{* 2}}+\frac{m^{*} v^{\prime \prime}}{u^{\prime}+\theta_{c} \chi^{\prime}(0)} .
$$

From (A1), there are three possibilities: (a) two positive and two negative characteristic roots, (b) four positive ones, and (c) four negative ones. As $\gamma$ changes from zero to infinity, the third term of (A2) increases from zero to infinity whereas the other three terms remain negative and unchanged since 
$c^{*}, k^{*}$ and $m^{*}$ that satisfy (23) do not depend on $\gamma$. Consequently $B_{3}$ changes from negative to positive. However, since $B_{0}>0$ for any positive $\gamma$, any root cannot be zero, implying that any root cannot change its sign as $\gamma$ changes. Since $B_{3}$ must be negative in case (b) and positive in case (c), cases (b) and (c) are ruled out and only case (a) is valid, implying the saddle path stability to hold and the path to be unique. ${ }^{7}$

\section{Appendix B The Dynamics of the Real Wage}

This appendix shows that $\dot{w} / w$ converges to zero if capital $k$ permanently accumulates.

First we treat the case where $m$ converges to a finite value. Since $\pi=0$ in this steady state, (21) implies

$$
\frac{\dot{w}}{w}=\gamma\left(l^{d}-1\right)
$$

where from (12) $l^{d}$ is

$$
l^{d}=\frac{k}{h(w)} .
$$

In the steady state, from (30) and (B2) we obtain

$$
\frac{\dot{l}^{d}}{l^{d}}=\frac{\dot{k}}{k}-\left[\lim _{w \rightarrow \infty} \frac{h^{\prime}(w) w}{h(w)}\right] \frac{\dot{w}}{w}=-\left[\lim _{w \rightarrow \infty} \frac{h^{\prime}(w) w}{h(w)}\right] \frac{\dot{w}}{w},
$$

where from $(12) h^{\prime}(w) \geq 0$. We here assume

$$
\lim _{w \rightarrow \infty} \frac{h^{\prime}(w) w}{h(w)}>0
$$

which is indeed the case under a production function of the Cobb-Douglas or CES type whose elasticity of substitution is greater than 1, as derived from (11) and (12). From (B1), (B3) and (B4) we obtain

$$
\frac{i^{d}}{l^{d}} \lesseqgtr 0 \Longleftrightarrow l^{d} \gtreqless 1 .
$$

\footnotetext{
${ }^{7}$ See, e.g., Gandolfo (1997, chapter 25) for this logic.
} 
Therefore, the labor market is stable and eventually $l^{d}=1$ and $\dot{w} / w=0$.

Next, we consider the case where $m$ as well as $k$ continues to expand. Since $\pi<0$ in the steady state, from (21)

$$
\frac{\dot{w}}{w}=\gamma\left(l^{d}-1\right)-\pi .
$$

Since from (B3)-(B5) we find

$$
\frac{i^{d}}{l^{d}} \lesseqgtr 0 \Longleftrightarrow l^{d} \gtreqless 1+\frac{\pi}{\gamma},
$$

$l^{d}$ converges to $1+\pi / \gamma(<1)$ and then $\dot{w} / w=0$.

\section{Appendix C Stability of Full Employment Growth}

Under full employment growth $w$ rises to infinity while $P$ stays finite. Therefore, $W$ increases to infinity and hence $l_{t}^{d}>1$ for $t<\infty$, as is clear from (20). Furthermore, $l_{t}^{d}$ converges to 1 , as shown in appendix B. Thus, from $(5)$

$$
l_{t}=1 \leq l_{t}^{d} .
$$

Replacing $k_{t}$ and $w_{t}$ by $b_{t}\left(\equiv k_{t}^{-1}\right)$ and $n_{t}\left(\equiv w_{t}^{-1}\right)$ respectively and applying the above property to (18), (19), (21) and (22) yields

$$
\begin{gathered}
\frac{\dot{c}_{t}}{c_{t}}=\sigma\left(c_{t}\right)\left[f^{\prime}\left(1 / b_{t}\right)+\frac{\theta_{k} \chi^{\prime}(0)}{u^{\prime}\left(c_{t}\right)+\theta_{c} \chi^{\prime}(0)}-\rho\right], \\
\dot{b}_{t}=-f\left(1 / b_{t}\right) b_{t}^{2}+c_{t} b_{t}^{2}, \\
\frac{\dot{n}_{t}}{n_{t}}=-\gamma\left(\frac{1}{h\left(1 / n_{t}\right) b_{t}}-1\right)+\frac{v^{\prime}\left(m_{t}\right)}{u^{\prime}\left(c_{t}\right)+\theta_{c} \chi^{\prime}(0)}-\frac{\chi^{\prime}(0)\left(\theta_{k}-\theta_{m}\right)}{u^{\prime}\left(c_{t}\right)+\theta_{c} \chi^{\prime}(0)}-f^{\prime}\left(1 / b_{t}\right), \\
\frac{\dot{m}_{t}}{m_{t}}=-\frac{v^{\prime}\left(m_{t}\right)}{u^{\prime}\left(c_{t}\right)+\theta_{c} \chi^{\prime}(0)}+\frac{\chi^{\prime}(0)\left(\theta_{k}-\theta_{m}\right)}{u^{\prime}\left(c_{t}\right)+\theta_{c} \chi^{\prime}(0)}+f^{\prime}\left(1 / b_{t}\right) .
\end{gathered}
$$


By linearizing (C1) around the steady state in which (29) holds and $c$ and $m$ are given by (27) and (28), we obtain the characteristic equation:

$$
\left|\begin{array}{cccc}
\zeta_{c}-z & -\sigma c f^{\prime \prime} / b^{2} & 0 & 0 \\
b^{2} & f^{\prime}-2(f-c) b-z & 0 & 0 \\
\psi n & n\left(f^{\prime \prime}+\gamma / h\right) / b^{2} & \zeta_{n}-z & -\zeta_{m} n / m \\
-\psi m & -f^{\prime \prime} m / b^{2} & 0 & \zeta_{m}-z
\end{array}\right|=0
$$

where

$$
\begin{aligned}
& \zeta_{c} \equiv-\frac{\theta_{k} \chi^{\prime}(0) \sigma c u^{\prime \prime}}{\left[u^{\prime}+\theta_{c} \chi^{\prime}(0)\right]^{2}}>0, \quad \zeta_{m} \equiv-\frac{v^{\prime \prime} m}{u^{\prime}+\theta_{c} \chi^{\prime}(0)}>0, \\
& \zeta_{n} \equiv-\gamma \frac{h^{\prime}(1 / n)}{h(1 / n) n}<0 \quad(\text { from }(\mathrm{B} 4)), \quad \psi \equiv-\frac{\left[v^{\prime}-\chi^{\prime}(0)\left(\theta_{k}-\theta_{m}\right)\right] u^{\prime \prime}}{\left[u^{\prime}+\theta_{c} \chi^{\prime}(0)\right]^{2}} .
\end{aligned}
$$

Therefore, the characteristic roots are $\zeta_{n}(<0), \quad \zeta_{m}(>0)$, and the two solutions of

$$
z^{2}-\left[\zeta_{c}+f^{\prime}-2(f-c) b\right] z+\zeta_{c}\left[f^{\prime} / b-2(f-c)\right] b+\sigma c f^{\prime \prime}=0 .
$$

Since $(w=) f-f^{\prime} k>0$ and $k(=1 / b)$ is large enough while $c$ is given by (27), we find

$$
f^{\prime} k-2(f(k)-c)<0
$$

implying that the constant term of (C3) is negative. Thus, there are two positive and two negative characteristic roots. Since the degree of freedom in choosing the initial values of $c_{t}, b_{t}, n_{t}$ and $m_{t}$ is two, the present dynamics is saddle path stable. 


\section{Appendix D Stability of Unemployment Growth}

By replacing $k_{t}, w_{t}$ and $m_{t}$ by $b_{t}\left(\equiv k_{t}^{-1}\right), n_{t}\left(\equiv w_{t}^{-1}\right)$ and $x_{t}\left(\equiv m_{t}^{-1}\right)$ respectively in (18), (19), (21) and (22), where $l_{t}=k_{t} / h\left(w_{t}\right)<1$, we obtain

$$
\begin{gathered}
\frac{\dot{c}_{t}}{c_{t}}=\sigma\left(c_{t}\right)\left[f^{\prime}\left(h\left(1 / n_{t}\right)\right)+\frac{\theta_{k} \chi^{\prime}(0)}{u^{\prime}\left(c_{t}\right)+\theta_{c} \chi^{\prime}(0)}-\rho\right], \\
\dot{b}_{t}=-f\left(h\left(1 / n_{t}\right)\right) b_{t} / h\left(1 / n_{t}\right)+c_{t} b_{t}^{2}, \\
\frac{\dot{n}_{t}}{n_{t}}=-\gamma\left(\frac{1}{h\left(1 / n_{t}\right) b_{t}}-1\right)+\frac{v^{\prime}\left(1 / x_{t}\right)}{u^{\prime}\left(c_{t}\right)+\theta_{c} \chi^{\prime}(0)}-\frac{\chi^{\prime}(0)\left(\theta_{k}-\theta_{m}\right)}{u^{\prime}\left(c_{t}\right)+\theta_{c} \chi^{\prime}(0)}-f^{\prime}\left(h\left(1 / n_{t}\right)\right), \\
\frac{\dot{x}_{t}}{x_{t}}=\frac{v^{\prime}\left(1 / x_{t}\right)}{u^{\prime}\left(c_{t}\right)+\theta_{c} \chi^{\prime}(0)}-\frac{\chi^{\prime}(0)\left(\theta_{k}-\theta_{m}\right)}{u^{\prime}\left(c_{t}\right)+\theta_{c} \chi^{\prime}(0)}-f^{\prime}\left(h\left(1 / n_{t}\right)\right)(=\pi<0) .
\end{gathered}
$$

Linearizing (D1) in the neighborhood of the steady state where $c$ is given by (27) and applying (12) to the result yields the following characteristic function:

$$
\left|\begin{array}{cccc}
\zeta_{c}-z & 0 & \frac{\sigma c}{h n^{2}} & 0 \\
b^{2} & -\frac{f}{h}+2 b c-z & \frac{b}{f^{\prime \prime} h^{3} n^{2}}\left(f-f^{\prime} h\right) & 0 \\
\psi n & \frac{\gamma n}{h b^{2}} & \frac{\gamma}{f^{\prime \prime} h^{3} b n}-\frac{1}{h n}-z & \zeta_{m} \frac{n}{x} \\
\psi x & 0 & -\frac{x}{h n^{2}} & \pi+\zeta_{m}-z
\end{array}\right|=0,
$$

where $\zeta_{c}, \psi$ and $\zeta_{m}$ are the same as those in $(\mathrm{C} 2)$.

In the present steady state $\zeta_{c}$ and $\psi$ are finite. Since $l<1$ and $k(=1 / b)$ and $m(=1 / x)$ continue to expand, using (1), (11) and (12) we find

$$
\begin{gathered}
f(h) / h=f(k / l) /(k / l)=0, \quad 1 / n=f(h)-f^{\prime}(h) h, \\
1 /(h n)=f(h) / h-f^{\prime}(h)=0, \quad b c=0, \quad \zeta_{m}=0, \quad h b=1 / l .
\end{gathered}
$$

Calculating (D2) and applying the above properties to the result leads to

$$
\left(\zeta_{c}-z\right)(\pi-z)\left[z^{2}-\frac{\gamma}{f^{\prime \prime} h^{3} b n} z-\frac{\gamma}{f^{\prime \prime} h^{4} b n}\left(f+\frac{1}{n}-\frac{2 c}{l}\right)\right]=0 .
$$


Therefore, two of the four roots are $\zeta_{c}(>0)$ and $\pi(<0)$ and the other two roots, $z_{1}$ and $z_{2}$, satisfy

$$
z_{1}+z_{2}=\frac{\gamma}{f^{\prime \prime} h^{3} b n}<0, \quad z_{1} z_{2}=-\frac{\gamma}{f^{\prime \prime} h^{4} b n}\left(f+\frac{1}{n}-\frac{2 c}{l}\right)>0,
$$

where the second inequality holds since $f$ and $1 / n(=w)$ continue to expand while $c / l$ is finite. These properties show that $z_{1}$ and $z_{2}$ are negative. Since there are one positive and three negative roots whereas the degree of freedom in choosing the initial values of $c_{t}, b_{t}, n_{t}$ and $x_{t}$ is two, the stability type of the present dynamics is sink.

\section{Appendix E Stability of Stagnation with Un- employment}

We replace $m_{t}$ by $x_{t}\left(=1 / m_{t}\right)$ and linearize (18), (19), (21) and (22), where $l_{t}=k_{t} / h\left(w_{t}\right)<1$, in the neighborhood of the steady state where $c, k$ and $l$ are given by (35) and $x=0$. By applying (1) and (12) to the results we obtain the characteristic function of the dynamics of $\left(c_{t}, k_{t}, w_{t}, x_{t}\right)$ :

$$
\left|\begin{array}{cccc}
-\frac{\theta_{k} \chi^{\prime}(0) \sigma c u^{\prime \prime}}{\left[u^{\prime}+\theta_{c} \chi^{\prime}(0)\right]^{2}}-z & 0 & -\frac{\sigma c l}{k} & 0 \\
-1 & \frac{f l}{k}-z & \frac{l^{3}}{f^{\prime \prime} k^{2}}\left(f-f^{\prime} \frac{k}{l}\right) & 0 \\
-\frac{\chi^{\prime}(0)\left(\theta_{k}-\theta_{m}\right) w u^{\prime \prime}}{\left[u^{\prime}+\theta_{c} \chi^{\prime}(0)\right]^{2}} & \frac{\gamma w l}{k} & -\frac{w l}{k}+\frac{\gamma w l^{3}}{f^{\prime \prime} k^{2}}-z & \frac{v^{\prime \prime}}{u^{\prime}+\theta_{c} \chi^{\prime}(0)} \frac{w}{x^{2}} \\
0 & 0 & 0 & \gamma(l-1)-z
\end{array}\right|=0 .
$$

It reduces to

$$
(\gamma(l-1)-z)\left(-z^{3}+\epsilon_{2} z^{2}+\epsilon_{1} z+\epsilon_{0}\right)=0
$$


where

$$
\begin{aligned}
\epsilon_{2} & \equiv-\frac{\theta_{k} \chi^{\prime}(0) \sigma c u^{\prime \prime}}{\left[u^{\prime}+\theta_{c} \chi^{\prime}(0)\right]^{2}}+\frac{f l}{k}-\frac{w l}{k}+\frac{\gamma w l^{3}}{f^{\prime \prime} k^{2}} \\
\epsilon_{1} & \equiv \frac{\theta_{k} \chi^{\prime}(0) \sigma c u^{\prime \prime}}{\left[u^{\prime}+\theta_{c} \chi^{\prime}(0)\right]^{2}}\left(\frac{f l}{k}+\frac{\gamma w l^{3}}{f^{\prime \prime} k^{2}}\right)-\frac{\theta_{m} \chi^{\prime}(0) \sigma c u^{\prime \prime}}{\left[u^{\prime}+\theta_{c} \chi^{\prime}(0)\right]^{2}} \frac{w l}{k}+\frac{f w l^{2}}{k^{2}}-\frac{\gamma f^{\prime} w l^{3}}{f^{\prime \prime} k^{2}}, \\
\epsilon_{0} & \equiv-\frac{\sigma c w l^{2}}{f^{\prime \prime} k^{2}}\left[\frac{\theta_{k} \chi^{\prime}(0) \gamma u^{\prime \prime} f^{\prime} l}{\left[u^{\prime}+\theta_{c} \chi^{\prime}(0)\right]^{2}}-f^{\prime \prime}\left(\gamma+\frac{\theta_{m} \chi^{\prime}(0) u^{\prime \prime} f}{\left[u^{\prime}+\theta_{c} \chi^{\prime}(0)\right]^{2}}\right)\right]<0 .
\end{aligned}
$$

Note that $\epsilon_{0}<0$ since from (36) and (40) the square bracket of the right-hand side of $\epsilon_{0}$ is negative.

One of the four roots of (E1) is obviously $\gamma(l-1)$, which is negative. Let $z_{1}, z_{2}$ and $z_{3}$, where $z_{1} \leq z_{2} \leq z_{3}$, denote the other three roots. Since $\epsilon_{0}=z_{1} z_{2} z_{3}<0$, there are two possibilities:

$$
\begin{aligned}
& z_{1}<0, z_{2}>0, z_{3}>0 \\
& z_{1}<0, z_{2}<0, z_{3}<0
\end{aligned}
$$

From the second property of (34) and the second equation of (E2),

$$
\epsilon_{1}>\frac{\theta_{k} \chi^{\prime}(0) \sigma c u^{\prime \prime}}{\left[u^{\prime}+\theta_{c} \chi^{\prime}(0)\right]^{2}}\left(\frac{f l}{k}-\frac{w l}{k}+\frac{\gamma w l^{3}}{f^{\prime \prime} k^{2}}\right)+\frac{f w l^{2}}{k^{2}}-\frac{\gamma f^{\prime} w l^{3}}{f^{\prime \prime} k^{2}},
$$

and hence

$$
\epsilon_{1}=-z_{1} z_{2}-z_{2} z_{3}-z_{3} z_{1}>0 \text { if } \frac{f l}{k}-\frac{w l}{k}+\frac{\gamma w l^{3}}{f^{\prime \prime} k^{2}} \leq 0 .
$$

From this property we find that only the first combination in (E3) is possible. Furthermore, from the first equation of (E2)

$$
\epsilon_{2}=z_{1}+z_{2}+z_{3}>0 \text { if } \frac{f l}{k}-\frac{w l}{k}+\frac{\gamma w l^{3}}{f^{\prime \prime} k^{2}}>0
$$

implying that only the first combination in (E3) is possible. Thus, there are always two negative and two positive characteristic roots and hence a unique dynamic path obtains since the degree of freedom in choosing the initial values of $c_{t}, k_{t}, w_{t}$ and $x_{t}$ is two. 


\section{References}

[1] Bakshi, G. S. and Z. Chen (1996), "The Spirit of Capitalism and StockMarket Prices," American Economic Review, Vol. 86, pp. 133-157.

[2] Blanchard, O. J. and S. Fischer (1989), Lectures on Macroeconomics, Cambridge, Massachusetts: The MIT Press.

[3] Clark, A. E. and A. J. Oswald (1998), "Comparison-Concave Utility and Following Behaviour in Social and Economic Settings," Journal of Public Economics, Vol. 70, pp. 133-155.

[4] Clemens, C. (2004), "Status, Risk-Taking and Intertemporal Substitution in an Endogenous Growth Model," Journal of Economics, Vol. 83, pp. 103-123.

[5] Cole, H. L., G. J. Mailath, and A. Postlewaite (1992), "Social Norms, Savings Behavior, and Growth," Journal of Political Economy, Vol. 100, pp. 1092-1125.

[6] Corneo, G. and O. Jeanne (1997a), "Conspicuous Consumption, Snobbism and Conformism," Journal of Public Economics, Vol. 66, pp. 55-71.

[7] (1997b), "On Relative Wealth Effects and the Optimality of Growth," Economics Letters, Vol. 54, pp. 87-92.

[8] Fershtman, C., K. M. Murphy, and Y. Weiss (1996), "Social Status, Education, and Growth," Journal of Political Economy, Vol. 104, pp. 108-132.

[9] Fisher, W. H. (2004), "Status Preference, Wealth and Dynamics in the Open Economy," German Economic Review, Vol. 5, pp. 335-355. 
[10] - (2005), "Current Account Dynamics in a Small Open-Economy Model of Status Seeking," Review of International Economic, Vol. 13, pp. 262-282.

[11] Futagami, K. and A. Shibata (1998), "Keeping One Step Ahead of the Joneses: Status, the Distribution of Wealth, and Long Run Growth," Journal of Economic Behavior and Organization, Vol. 36, pp. 109-126.

[12] Gandolfo, G. (1997), Economic Dynamics: Study Edition, Berlin: Springer-Verlag.

[13] Gong, L. and H. Zou (2001), "Money, Social Status, and Capital Accumulation in a Cash-in-Advance Model," Journal of Money, Credit, and Banking, Vol. 33, pp. 284-293.

[14] Kawamoto, K. (2007), "Preferences for Educational Status, Human Capital Accumulation, and Growth," Journal of Economics, Vol. 91, pp. 41-67.

[15] Keynes, J. M. (1936), The General Theory of Employment, Interest and Money, London: Macmillan.

[16] (1972), "Economic Possibilities for Our Grandchildren", in Essays in Persuasion, The Collected Writings of John Maynard Keynes, Vol. IX, London: Macmillan, pp. 321-332. Originally Published in 1930.

[17] Long, N. V. and K. Shimomura (2004), "Relative Wealth, StatusSeeking, and Catching-Up," Journal of Economic Behavior and Organization, Vol. 53, pp. 529-542.

[18] Ono, Y. (1994), Money, Interest and Stagnation, New York: Oxford University Press. 
[19] (2001), "A Reinterpretation of Chapter 17 of Keynes's General Theory: Effective Demand Shortage under Dynamic Optimization," International Economic Review, Vol. 42, pp. 207-236.

[20] Rauscher, M. (1997), "Conspicuous Consumption, Economic Growth, and Taxation," Journal of Economics, Vol. 66, pp. 35-42.

[21] Smith, A. (1910), The Wealth of Nations; introduction by Edwin R. A. Seligman, Vol. 1, New York: Dutton. Originally Published in 1776.

[22] Veblen, T. (1922), The Theory of the Leisure Class. An Economic Study of Institutions, London: George Allen Unwin. Originally Published in 1899.

[23] Weber, M. (1958), The Protestant Ethic and the Spirit of Capitalism, New York: Charles Scribner's Sons. Originally Published in 1904.

[24] Weiss, Y. and C. Fershtman (1998), "Social Status and Economic Performance: A Survey," European Economic Review, Vol. 42, pp. 801-820.

[25] Zou, H. (1994), "The Spirit of Capitalism' and Long-Run Growth," European Journal of Political Economy, Vol. 10, pp. 279-293.

[26] (1995), "The Spirit of Capitalism and Saving Behavior," Journal of Economic Behavior and Organization, Vol. 28, pp. 131-143.

[27] (1998), "The Spirit of Capitalism, Social Status, Money, and Accumulation," Journal of Economics, Vol. 68, pp. 219-233. 


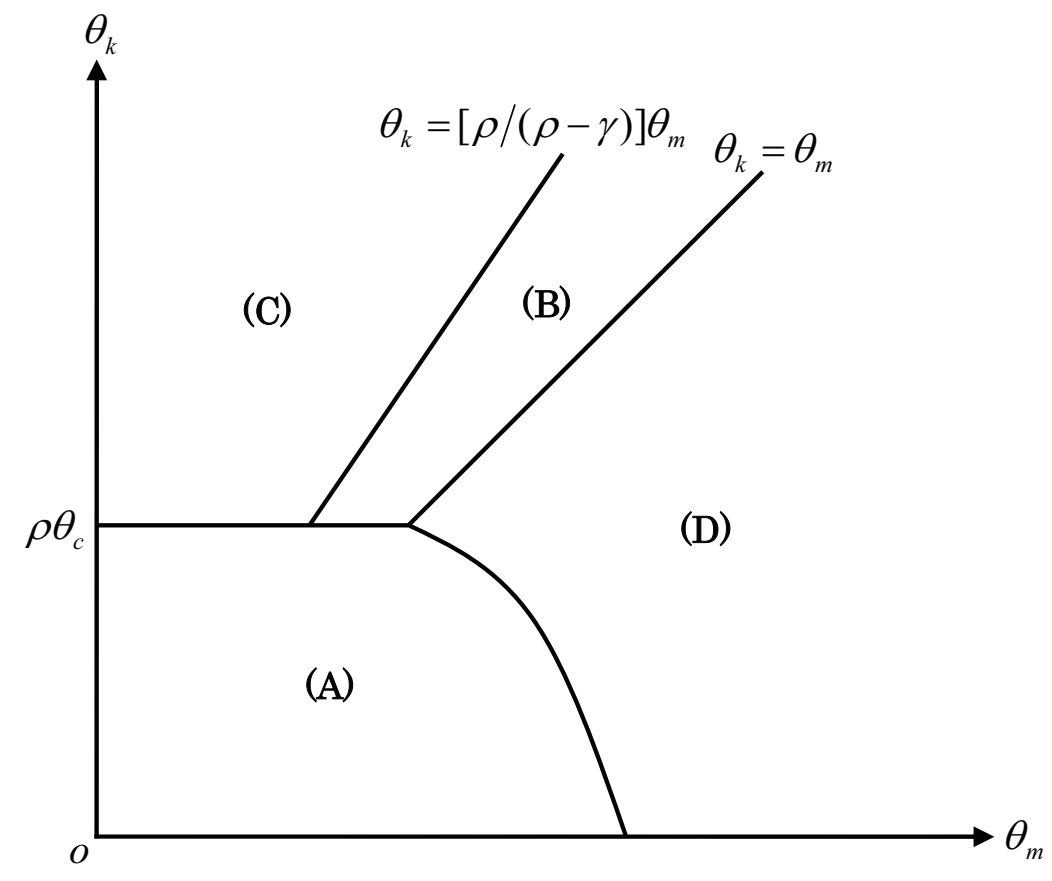
(A) Full Employment Steady State
(B) Full Employment Growth or Unemployment Growth
(C) Full Employment Growth
(D) Stagnation with Persistent Unemployment

Figure 1: Growth and Stagnation Patterns $(\rho>\gamma)$ 


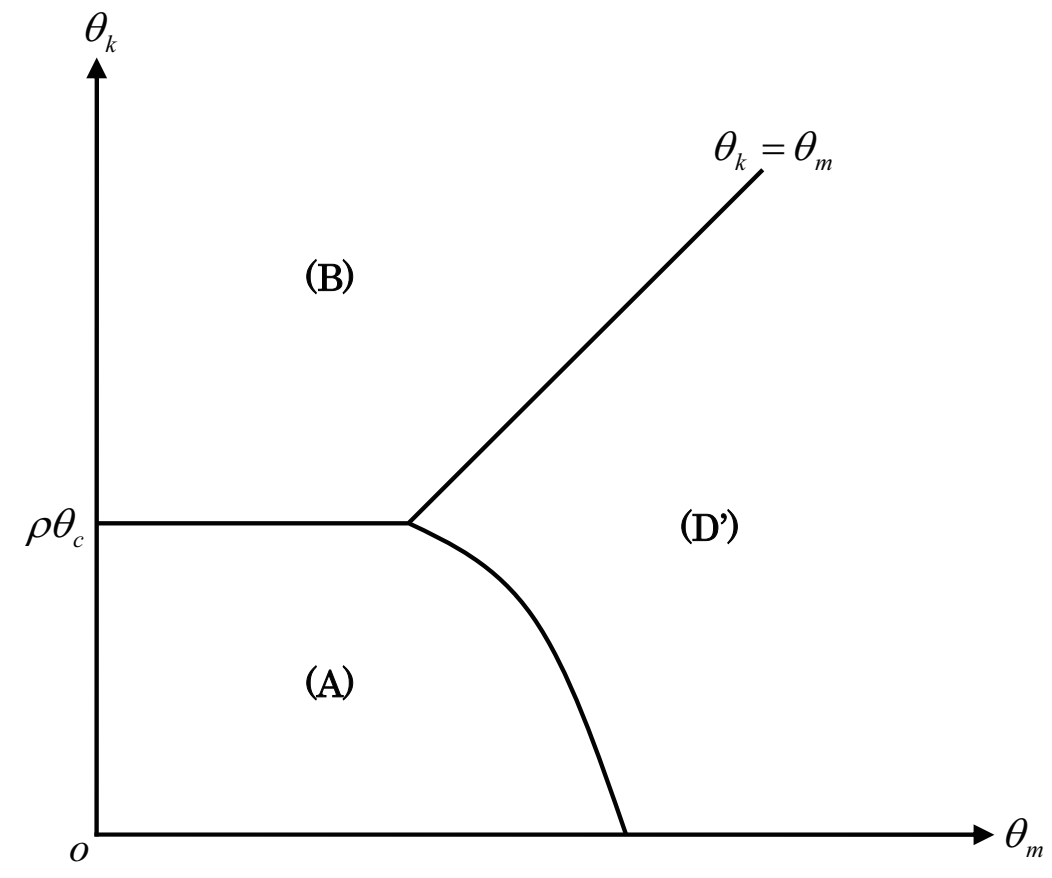

(A) Full Employment Steady State

(B) Full Employment Growth or Unemployment Growth

(D') No Equilibrium Path

Figure 2: Growth and Stagnation Patterns $(\rho \leq \gamma)$ 